\title{
Service Excellent Rumah Makan Padang Dalam Perspektif Wisata Islami
}

\author{
Yunia Wardi ${ }^{*}$, Abror $^{2}$, Okki Trinanda ${ }^{3}$ \\ 1,2,3 Universitas PGRI Semarang
}

\section{A R T I C L E I N F O}

Article history:

Received 20 May 2019

Received in revised form 10 June 2019

Accepted 30 July 2019

Available online 30 August 2019

Kata Kunci:

Service Excellent, Wisata

Islami

Keywords:

Service Excellent, Islamic

Tourism

\begin{abstract}
A B S T R A K
Padang Restaurant adalah salah satu restoran etnik di Indonesia dari Minangkabau. Berbeda dengan kantin, kafe atau restoran, di mana pengunjung diberikan menu dan memesan makanan yang diinginkan, di restoran Padang, ketika pengunjung duduk, mereka akan dilayani dengan berbagai pilihan lauk yang tersedia dengan piring kecil. Setelah melayani maka pelanggan hanya mengambil apa yang diinginkannya dari meja makan. Selain itu, penyimpanan makanan juga dilakukan di tempat terbuka sehingga pengunjung bisa datang. Hal-hal ini tentunya akan membawa masalah kebersihan. Bagi pengunjung yang sangat memperhatikan kebersihan, tentu saja mereka akan merasa tidak nyaman melihat makanan yang telah disajikan di meja lain dan kemudian disajikan di atas meja. Atau lihat makanan yang disajikan dibawa dari tempat terbuka. Keunggulan Layanan di restoran tidak
\end{abstract} hanya meningkatkan laba perusahaan tetapi juga dapat meningkatkan citra restoran. Ketika tamu atau konsumen puas dengan layanan di restoran mereka, mereka akan mempromosikan kepuasan mereka di restoran. Service Excellence adalah layanan kepada konsumen untuk meningkatkan layanan di perusahaan. Service Excellence in Restaurants adalah layanan kepada konsumen untuk memberikan kepuasan dalam bentuk pelayanan prima kepada produk restoran. Layanan prima sangat penting tidak hanya untuk mendapatkan keuntungan besar tetapi layanan ini harus dipenuhi oleh setiap perusahaan.

\section{A B S T R A C T}

Padang Restaurant is one of the ethnic restaurants in Indonesia from Minangkabau.. Unlike the canteen, cafe or restaurant, where visitors are given a menu and order the desired food, at the Padang restaurant, when visitors sit, they will be served a whole selection of side dishes available with small plates. After serving then the customer just takes what he wants from the dish table. In addition, food storage is also done in an open place so that visitors can come. These things will certainly bring cleanliness problems. For visitors who are very concerned about cleanliness, of course they will feel uncomfortable seeing the food that has been served at another table and then served on the table. Or see the food served brought from an open place. Service Excellence at the restaurant not only increases the company's profit but can also improve the image of the restaurant. When guests or consumers are satisfied with the service in their restaurant they will promote their satisfaction in the restaurant. Service Excellence is service to consumers to improve service in a company. Service Excellence in Restaurants is a service to consumers to provide satisfaction in the form of excellent service to the restaurant products. Excellent service is very important not only to get big profits but this service must be fulfilled by every company. To provide Service Excellence in the right restaurant, every employee must get training or training so that they are truly able to work well and professionally. A restaurant employee must be able to provide services to consumers whoever they are. Not only employees who are in front but all members of the company must also be able to provide the best service.

Copyright (C) Universitas Pendidikan Ganesha. All rights reserved.

\footnotetext{
* Corresponding author.

E-mail addresses: yuniawardi@gmail.com (Yunia Wardi)
} 


\section{Pendahuluan}

Bagi masyarakat Indonesia terutama di Sumatera Barat, kuliner merupakan salah satu bentuk ekspresi kebudayaan.Demikian pula bagi masyarakat Minangkabau, makan merupakan salah satu bagian penting di dalam kebudayaannya.Sehingga banyak sekali aktifitas budaya dan keseharian dari masyarakat Padang yang melibatkan "makan".Oleh karena itu, maka wajar kiranya apabila masakan Padang memiliki rasa yang enak, serta pilihan masakan berbagai rasa dan ragam.

Di luar Sumatera Barat, orang mengenal masakan Minang dengan sebutan "masakan Padang”.Hal ini sesuai dengan kebiasaan menggantikan panggilan "Orang Minang" dengan "Orang Padang".

Rumah Makan Padang merupakan salah satu rumah makan etnis di Indonesia yang berasal dari Minangkabau. Keberadaan dan "merek" Rumah Makan Padang telah sangat dikenal di wilayah Indonesia dan bahkan hingga di beberapa negara tetangga seperti Australia, Singapura, Malaysia dan negara-negara lain yang didiami oleh etnis Melayu. Masakan Padang tersebut, dengan rasa dan ragamnya, saat ini begitu diminati oleh masyarakat secara luas.

Berbeda dengan kantin, kafe ataupun Rumah makan, dimana pengunjung diberikan menu dan memesan makanan yang diinginkan, di rumah makan Padang pada saat pengunjung duduk, ia akan dihidangkan seluruh pilihan lauk pauk yang tersedia dengan piring-piring kecil. Setelah dihidangkan kemudian pelanggan tinggal mengambil apa yang diinginkan dari atas meja hidangan.

Persoalan yang kemudian bisa muncul adalah pada makanan yang telah dihidangkan, namun tidak dimakan oleh pengunjung. Makanan tersebut akan dibawa kembali dan dihidangkan ke meja lain. Tidak jarang makanan yang masih ada di meja pengunjung, ditraik kembali untuk dihidangkan di meja lain.

Selain itu, penyimpanan makan juga dilakukan di tempat terbuka agar bisa dilihat oleh pengunjung yang datang. Hal-hal tersebut tentu akan mendatangkan permasalahan kebersihan. Bagi pengunjung yang sangat memperhatikan kebersihan, tentu akan merasa tidak nyaman melihat makanan yang sudah dihidangkan di meja lain kemudian dihidangkan di mejanya. Atau melihat makanan yang dihidangkan di datangkan dari tempat yang terbuka.

Hal lain yang merupakan ciri khas rumah makan Padang adalah aspek harga. Jika pengunjung datang, pelayan tidak akan menanyakan menu apa yang diinginkan, namun langsung menghidangkan semua jenis masakan dalam piring-piring kecil. Nanti jika pengunjung selesai makan, sebelum hidangan di ambil kembali pelayan akan menghitung apa saja yang telah dimakan.

Bagi pengunjung reguler, hal ini bukan merupakan suatu yang aneh.Namun bagi pengunjung yang jarang datang atau baru pertama kali, harga masakan yang diambil tidak diketahui. Harga makanan baru akan diketahui setelah selesai makan dan dihitung. Kebijakan harga ini disebut sebagai miracle price (Elfindri, 2015), dimana harga tidak diketahui oleh konsumen hingga setelah konsumen selesai mengkonsumsinya.

Kebijakan miracle price di rumah makan padang seringkali menghasilkan keluhan bagi pengunjung. Fenomena ini terjadi terutama di saat-saat musim libur, dimana jumlah pengunjung meningkat. Disebabkan oleh karena ketidaktahuan pengunjung akan harga makanan, maka kerap terjadi pengunjung yang kecewa karena tagihan dianggap terlalu tinggi dan tidak wajar. Ketidak adilan harga dari rumah makan ini bahkan sudah memiliki istilah sendiri di masyarakat Sumatera Barat, yaitu "mamakuak".

Laporan dari masyarakat terhadap perilaku mamakuak ini telah menjadi perhatian pemerintah Provinsi Sumatera Barat melalui Dinas Pariwisata Sumatera Barat (rakyatsumbarnews.com, 2017). Pemerintah merasa khawatir, dengan adanya perilaku mamakuak, terutama rumah-rumah makan di tempat wisata, akan menimbulkan citra negatif terhadap pariwisata Sumatera Barat.

Berbagai fenomena diatas dapat mempengaruhi kepuasan, citra rumah makan padang dan pada akhirnya loyalitas terhadap rumah makan itu sendiri. Meskipun rumah makan Padang memiliki jaminan halal, namun resiko kesehatan serta miracle price yang dijalankan bisa menimbulkan disonansi kognitif.

Disonansi Kognitif merupakan perasaan ketidaknyamanan seseorang akibat sikap, pemikiran, dan perilaku yang saling bertentangan dan memotivasi seseorang untuk mengambil langkah demi mengurangi ketidaknyamanan tersebut (West \& Turner, 2008). Artinya, pengunjung yang mendapatkan pengalaman yang tidak baik, akan merasa tidak nyaman dan tidak berminat kembali untuk mengunjungi rumah makan padang.

Service Excellence di Rumah makan bukan hanya meningkatkan profit perusahaan namun juga bisa meningkatkan citra Rumah makan tersebut. Saat tamu atau konsumen merasa puas dengan pelayanan di Rumah makan mereka akan mempromosikan kepuasan mereka pada Rumah makan tersebut.

Service Excellence adalah pelayanan pada konsumen untuk meningkatkan pelayanan pada suatu perusahaan.Service Excellence di Rumah makan merupakan pelayanan kepada konsumen untuk memberikan kepuasan berupa layanan prima terhadap produk Rumah makan tersebut. Pelayanan prima 
sangat penting bukan hanya mendapatkan profit besar namun pelayanan ini memang harus dipenuhi oleh setiap perusahaan.

Untuk memberikan Service Excellence di Rumah makan yang tepat, setiap karyawan harus mendapatkan pelatihan atau training agar mereka benar-benar mampu bekerja dengan baik dan profesional.Seorang karyawan Rumah makan harus bisa memberikan pelayanan kepada konsumen siapapun mereka. Bukan hanya karyawan yang berada di depan namun semua anggota perusahaan juga harus bisa memberikan pelayanan terbaik.

Pelatihan konsep Service Excellent dimaksudkan untuk memberikan pemahaman mendasar mengenai pentingnya Service Excellent serta strategi-strategi praktis dan kongkrit yang dapat dilaksanakan oleh RM Padang. Dalam kegiatan pelatihan ini, akan didatangkan tiga orang narasumber dengan latar belakang berbeda, untuk alasan yang berbeda pula.

1. Akademisi di Bidang Manajemen Pemasaran Jasa

Manajemen Pemasaran Jasa merupakan salah satu bagian dari Manajemen Pemasaran yang mengkaji tentang Pelayanan/ Service.Oleh karena itu, akademisi di bidang ini menguasai aspek-aspek pemasaran terutama dalam hal pelayanan dan lain sebagainya.Tugas akademisi sebagai pengisi sesi pertama pada pelatihan pertama adalah untuk memberikan gambaran mengenai pentingnya service excellent, serta memberikan contoh-contoh.

Saat ini di saat persaingan di berbagai industri yang semakin tinggi, aspek yang dilihat oleh calon pelanggan bukan lagi sekedar kualitas produk.Namun juga aspek-aspek lain seperti pelayanan yang baik sehingga pelanggan menjadi loyal.

2. Pusat Kajian Halal

Pada sesi kedua akan didatangkan narasumber dari Pusat Kajian Halal untuk mengkaji Aspek Islami/ Halal dari Rumah Makan Padang. Tujuan dari mendatangkan narasumber ini adalah supaya RM Padang di Kota Padang mendapatkan pemahaman mengenai kehalalan makanan, terutama keterkaitannya dengan service excellent di dunia kuliner.

3. Dinas Pariwisata Kota Padang

Strategi mendatangkan narasumber dari Dinas Pariwisata Kota Padang memiliki dua tujuan.Pertama agar pelaku RM Padang mengetahui berbagai kebijakan pemerintah, terutama Dinas Pariwisata sehubungan dengan pengembangan produk-produk ekonomi kreatif terutama kuliner.Sehingga, dengan demikian kelompok RM Padang memiliki informasi aktual dari tangan pertama, dan dapat menyesuaikan program pengembangan mereka agar sejalan dengan program pemerintah.Kedua, dengan kehadiran narasumber dari Dinas Pariwisata diharapkan akan muncul ikatan emosional antara Dinas Pariwisata dan pelaku RM Padang yang pada akhirnya akan menguntungkan kedua belah pihak.

\section{Metode}

\section{Persiapan Kegiatan}

Persiapan kegiatan dilaksanakan dengan mensurvei kebutuhan masyarakat khususnya pelaku Rumah Makan Padang selaku audiens.Selanjutnya melakukan kajian pustaka terkait strategi-strategi service excellent yang memang dibutuhkan oleh mereka. Berdasarkan hasil kajian serta diskusi, maka Narasumber pada acara Pelatihan ini adalah: 1) Medi Iswandi, ST., MM (Kepala Dinas Pariwisata Kota Padang), 2) Prof. Dr. Ir. Anni Faridah, M.Si (Pusat Kajian Halal Universitas Negeri Padang), dan 3) Dr. Yuliana, SP., M.Si (Dosen Fakultas Pariwisata Universitas Negeri Padang)

Pembagian undangan dan pengurusan ijin kegiatan, dilaksanakan satu minggu sebelum kegiatan dilaksanakan.Selanjutnya, untuk memastikan kehadriran para undangan, setiap peserta dikonfirmasi kembali melalui telepon pada h-1. Jika diketahui terdapat peserta yang tidak dapat hadir, maka akan diminta untuk mendatangkan perwakilan sebagai pengganti. Pada tahapan kegiatan ini, para pelaku pengabdian tidak mengalami kendala apapun.

Pelaksanaan Kegiatan

Kegiatan ini dilaksanakan pada tanggal 18 Oktober 2018 di Ruang Sidang Fakultas Ekonomi Universitas Negeri Padang. Adapun rundown acara pada hari tersebut diantaranya: Registrasi Peserta. Pembukaan oleh Ketua Tim Pengabdian, Prof Dr. Yunia Wardi, Drs., M.Si

\section{Hasil dan pembahasan}

Dalam pembukaan, Ketua Tim menyampaikan hasil penelitian yang telah dilakukan pada tahun 2017 lalu, yang bertemakan "Pariwisata Halal" serta penelitian yang dilakukan pada saat ini yaitu "Rumah Makan Padang Sebagai Aset Pariwisata". Ia menyampaikan bahwa Rumah Makan Padang merupakan 
salah satu aset berharga yang dapat mendorong pengembangan potensi pariwisata Sumatera Barat. Hal ini karena Rumah Makan Padang telah memiliki nama yang sangat populer dan rasa yang diminati oleh masyarakat. Salah satu hal yang masih bisa disempurnakan pada RMP adalah faktor pelayanan.Seperti pelayanan menghidangkan yang baik, kepastian harga, faktor kebersihan dan lain sebagainya.Oleh karena itu, berkaitan dengan enelitian yang telah dilaksanakan, maka Tim Pengabdian berinisiatif untuk melakukan pengabdian Pelatihan Service Excellent Pada Pelaku Rumah Makan Padang di Kota Padang Dalam Perspektif Wisata Islami. Oleh karena itu, Prof Dr. Yunia Wardi, Drs., M.Si berharap agar kegiatan ini dapat dikuti dengan serius oleh para peserta dan dapat membawa manfaat dalam pengembangan RMP kedepan.

Penyampaian Materi oleh Medi Iswandi, ST., MM (Kepala Dinas Pariwisata Kota Padang)

Rumah Makan Padang dibangun untuk memberikan pelayanan kepada tamu dalam hal makanan dan minuman.Saat tamu merasa puas dengan pelayanan dan makanan, berarti Rumah Makan Padang tersebut bisa memberikan Service Excellence yang baik.Pelayanan yang baik sangat diperlukan agar perusahaan bisa mendapatkan keuntungan yang maksimal.

Service Excellence di Rumah Makan Padang bukan hanya meningkatkan profit perusahaan namun juga bisa meningkatkan citra Rumah Makan Padang tersebut. Saat tamu atau konsumen merasa puas dengan pelayanan di Rumah Makan Padang mereka akan mempromosikan kepuasan mereka pada Rumah Makan Padang tersebut.

Service Excellence adalah pelayanan pada konsumen untuk meningkatkan pelayanan pada suatu perusahaan. Service Excellence di Rumah Makan Padang merupakan pelayanan kepada konsumen untuk memberikan kepuasan berupa layanan prima terhadap produk Rumah Makan Padang tersebut. Pelayanan prima sangat penting bukan hanya mendapatkan profit besar namun pelayanan ini memang harus dipenuhi oleh setiap perusahaan.

Untuk memberikan Service Excellence di Rumah Makan Padang yang tepat, setiap karyawan harus mendapatkan pelatihan atau training agar mereka benar-benar mampu bekerja dengan baik dan profesional.Seorang karyawan Rumah Makan Padang harus bisa memberikan pelayanan kepada konsumen siapapun mereka. Bukan hanya karyawan yang berada di depan namun semua anggota perusahaan juga harus bisa memberikan pelayanan terbaik.

Service Excellence di Rumah Makan Padang bisa dilakukan dengan berbagai cara termasuk penampilan karyawan atau performanya, cara penyajian hidangan, suasana Rumah Makan Padang, cara memberikan pelayanan yang cepat dan juga cara memperlakukan konsumen ketika mereka selesai makan. Untuk penampilan setiap karyawan, mereka harus berpenampilan yang rapi, menarik dan sopan.Setiap karyawan harus menggunakan seragam kerja yang telah ditentukan perusahaan.

Ketika konsumen datang segera disambut dengan senyuman dan sapaan ramah.Segera tamu diarahkan menuju tempat duduk. Pelayan memberikan daftar menu kepada tamu dan menanyakan apa yang mereka pesan. Setiap pesanan tamu harus dicatat dan tidak boleh terlupakan atau keliru.

Penyajian makanan yang tepat dan cepat juga akan meningkatkan Service Excellence di Rumah Makan Padang. Saat tamu mendapatkan apa yang mereka inginkan disajikan dengan cepat dan sesuai permintaan ini adalah kepuasan bagi mereka. Pelayanan yang baik dari Rumah Makan Padang dapat ditingkatkan dengan pelatihan atau training.

Penyampaian Materi oleh Prof. Dr. Ir. Anni Faridah, M.Si (Pusat Kajian Halal Universitas Negeri Padang)

Materi yang disampaikan oleh Prof. Dr. Ir. Anni Faridah berjudul "Titik Kritis Makanan Halal Untuk Service Excellent Rumah Makan Padang”. Bagian-bagian tubuh babi ternyata sangat luas digunakan orang, sebagai bahan baku industri dengan jenis pemanfaatan berbeda yang jumlahnya tidak terbayangkan. Lemak babi digunakan dalam pangsit, sosis, kosmetik, penyedap, falvor, margarin, dan sebagainya.Dagingnya digunakan dalam shorteninng, penyedap, burger, ham.Kulitnya digunakan kolagen.Tulangnya untuk karbon aktif.Gelatin babi untuk emulsi, jeli, cangkang kapsul, permen, dll.Bulu babi dipakai untuk kuas dan sistein.Jeroan babi lebih luas lagi seperti untuk kerupuk, porcine, rennin, insulin, dan kosmetik. Demikian luasnya pemakaian tubuh babi sehingga harus menjadi perhatian serius harus bagi konsumen muslim baik dalam hal makanan, pakaian, kosmetik, perangkat rumah, dan obatobatan agar terhindar dari kontaminasi zat haram.

Oleh karena itu, Rumah Makan Padang sebagai restoran yang telah terjamin kehalalannya, dapat menjadi ikon penting dalam menjaga aspek Wisata Halal.Semenjak dahulu Rumah Makan Padang telah terjamin kehalalannya. Namun hal yang harus diingat adalah, aspek halal bukan didapatkan dari bahanbahan makanan saja, namun juga cara pengolahan yang sesuai dengan syariat Islam. 
Penyampaian Dr. Yuliana, SP., M.Si (Dosen Fakultas Pariwisata Universitas Negeri Padang)

Pelayanan prima berarti memelihara dan mempertahankan pelanggan kita dan menambah pelanggan baru.Banyak aspek yang dapat memberikan kepuasan pelanggan dan bukan hanya sekedar memberikan yang terbaik.Hubungan yang berlanjut dan berkesinambungan antara penjual dan pelanggan belum diperhatikan dengan baik.Pelayanan prima juga bukan hanya sekedar memberikan suatu layanan, hal ini memerlukan sedikit pelayanan ekstra dan sesuai dengan harapan pelanggan yang mengharapkan pelayanan yang terbaik.Ini berarti membuat karyawan yang bekerja di Rumah Makan Padang melakukan pilihan, langkah, sikap dalam berhubungan dengan pelanggan yang tepat.Kualitas pelayanan suatu Rumah Makan Padang juga berperan penting dalam merangkul konsumen.Dengan kualitas pelayanan yang memuaskan, mendorong konsumen untuk berkunjung ataupun untuk melakukan pembelian ulang. Jika suatu Rumah Makan Padang mampu memberikan pelayanan yang baik, secara langsung atau tidak langsung, citra layanannya akan tersebar luas karena kepuasan yang dirasakan pelanggannya akan disampaikan pelanggan yang satu ke pelanggan lainnya secara berantai. Quality is what customers perceive. Customers buying service consider everything that contributes to the process and the final outcome in making thei assessments of the service. Keputusan Pembelian yaitu beberapa tahapan yang dilakukan oleh konsumen sebelum melakukan keputusan pembelian suatu produk. Sehingga sangat penting bagi suatu Rumah Makan Padang dalam bidang hospitality untuk terus-menerus memperhatikan dan mengevaluasi kualitas pelayanan, maupun produk yang ditawarkan pada konsumen, karena konsumen cenderung mengingat informasi-informasi yang mendukung tanggapan atau persepsi mereka untuk membeli produk tersebut.

\section{Simpulan dan saran}

Dari kegiatan Pelatihan Service Excellent Kepada Para Pelaku Rumah Makandi Kota Padang dapat disimpulkan bahwa: Pengetahuan dan keterampilan para pelaku rumah makan dapat meningkat dalam hal service excellent. Kegiatan ini merupakan implementasi dari penelitian yang telah dilaksanakan oleh tim

Selanjutnya, setelah melaksanakan kegiatan maka saran yang dapat diberikan diantaranya: Tim kegiatan Pengabdian Kepada Masyarakat melanjutkan proses kegiatan sehingga dapat menghasilkan luaran yang telah dirumuskan sebelumnya.

Untuk meningkatkan keterampilan pelaku Rumah Makan Padang, maka kegiatan ini dapat dilanjutkan dengan pelatihan-pelatihan berikutnya, dengan peserta yang sama

\section{Daftar Rujukan}

Battour,Mohamed \& Moh.NazariIsmail .2015. HalalTourism: Concepts, Practises, Challenges And Future. Tourism Management Perspective Journal Vol:6, No:11

Marks, L. D., \& Dollahite, D. C. 2001.Religion, relationships, and responsible fathering in latter-day saint families of children with special needs. Journal of Social and Personal Relationships, 18(5)

Wang, Y., and D. R. Fesenmaier. 2004. Towards Understanding Members' General Participation in and Active Contribution to an Online Travel Community. TourismManagement, 25 (6):709-22. 